\title{
JUNG, MANDALA E ARQUITETURA ISLÂMICA
}

\section{Rafael Raffaelli}

Resumo: Este artigo se propõe a refletir sobre as origens do conceito junguiano de mandala. Utiliza-se o relato autobiográfico de Jung, Memórias, Sonhos e Reflexões, e sua obra Psicologia e Alquimia para traçar essa origem. Segundo Barbara Hannah, biógrafa de Jung, uma mesquita no Cairo (Egito) foi de importância capital para a formulação desse conceito. Provavelmente esse templo é a Mesquita Ahmad Ibn Tulun. É analisada a relação entre a simbologia arquitetônica islâmica inspirada pelo sufismo e as concepções psicológicas de Jung.

Palavras-chave: Jung, Carl Gustav, 1875-1961. Mandala. Arquitetura islâmica. Mesquita Ahmad Ibn Tulun. Sufismo.

\section{Introdução}

"Mandala" - termo originado do sânscrito que significa "círculo" e "particularmente círculo mágico" (Jung \&Wilhelm, 1929/1983, p. 38) - designa as figuras geométricas formadas a partir do centro de um círculo ou de um quadrado, configurando um espaço sagrado.

Essas formas plásticas são usualmente utilizadas como instrumentos de concentração na prática meditativa, podendo ser moldadas em areia, desenhadas, pintadas ou configuradas através de técnicas mistas com o emprego de alto-relevo em madeira ou metal; podem ser igualmente expressas por meio dos movimentos e da dança, individual ou coletiva, em coreografias circulares' ${ }^{1}$. São também bastante em- 
pregadas em arquitetura, tanto no que se refere à planta das edificações quanto aos motivos decorativos. Além disso, são produzidas espontaneamente em visões, sonhos e fantasias, e diversos motivos mitológicos a ela se referem, como, por exemplo, o do labirinto.

Carl Gustav Jung (1875-1961) incorporou a ideia do mandala em sua Psicologia Analítica, como o símbolo que expressa o Si-mesmo, o arquétipo da totalidade, ápice do processo de individuação. Para ele esse símbolo é uma constante em todas as culturas, religiões e práticas esotéricas, pois aponta para a convergência em direção a um ponto central, o centro da psique objetiva2:"Mandala exprime o Si-mesmo, a totalidade da personalidade" (Jung, 1961/1985, p. 173).

Assim, segundo Jung (1961/1985), o mandala simboliza o caminho que leva à individuação, e se constitui na "descoberta última a que poderia chegar" (p. 174).

Mas onde, em sua vida e obra, podemos encontrar indicações sobre a história da associação entre esse símbolo ancestral e a Psicologia Analítica?

\section{O Contato de Jung com o Mandala}

Em seu relato autobiográfico Memórias, Sonhos e Reflexões, Jung (1961/1985) relata ter pintado seu primeiro mandala em 1916 de modo espontâneo, sem que pudesse atinar com o seu significado. Nos anos seguintes desenhou, pintou e esculpiu diversos mandalas como uma forma de expressar artisticamente os conteúdos de sua psique.

O reconhecimento da importância psicológica desse símbolo tomou corpo entre 1918 e 1920, tendo-se consolidado através de um sonho de 1927 , no qual Jung caminhava por uma cidade (Liverpool ${ }^{3}$ ) imersa na neblina até chegar numa praça na qual todas as ruas desembocavam, numa disposição radial; no centro da praça havia um lago e, no centro desse lago, uma ilha onde o sol brilhava e na qual vicejava uma magnólia coberta de flores rubras. Desse sonho derivou uma pintura que ele denominou "A Janela para a Eternidade", em cujo centro havia um castelo de aparência chinesa (Jung, 1961/1985, p. 175).

2 Jung (1944/1990) em Psicologia e Alquimia usa esse conceito como uma variante da expressão "inconsciente coletivo" (p. 53); de forma alternativa, ele empregou na mesma obra o termo"psique coletiva" (p.66). A "psique objetiva" ou "psique coletiva" seria composta de arquétipos, enquanto a "psique subjetiva" ou "psique individual" seria formada pelos complexos e se constituiria no lócus da consciência.

3 Jung (1961/1985) interpreta essa denominação como "the pool of life",i.e.,o"lago da vida", pois "liver" (fígado) é tradicionalmente encarado como a"sede da vida" (p. 176). 
Após esse sonho, em 1928 ou 19294, Jung recebeu correspondência do sinólogo Richard Wilhelm, solicitando um comentário à sua tradução de O Segredo da Flor de Ouro, texto chinês esotérico do século XVIII. Impressionado pela sincronicidade desse evento, Jung incluiu no seu texto uma reprodução do mandala intuído em sonhos (Jung \& Wilhelm, 1929/1983, p. 80), compreendendo afinal que ela representava o Si-mesmo e que "o Si-mesmo é um princípio, um arquétipo da orientação e do sentido" (Jung, 1961/1985, p. 176).

A orientação que o Si-mesmo propicia decorre da circumambulatio ${ }^{5}$, isto é, circum-ambulação, ou circulação em redor a um centro, configurando um círculo. Esse círculo - que á o próprio mandala - separa o espaço sagrado do espaço profano e dá forma a um temenos ${ }^{6}$ ou a um recipiente (Vaso de Hermes) no qual a metamorfose alquímica ${ }^{7}$ tem lugar. Em termos psicológicos, a circum-ambulação seria o ato de "mover-se em círculo em torno de si mesmo" (Jung, 1929/1983, p. 41), envolvendo a totalidade da personalidade. Ao longo do desenvolvimento da psique o movimento circular em relação a um ponto central configura-se numa espiral: "A espiral acentua o ponto central e portanto o útero, sinônimo freqüente do vaso alquímico. Ele também é um dos significados básicos do mandala oriental" (Jung, 1944/1990, p. 191).

No budismo Vajrayana ${ }^{8}$ - mais conhecido como budismo tibetano, embora não esteja restrito ao Tibete - o mandala ('khilkor', em tibetano) ocupa um papel importante nas técnicas de meditação, pois simboliza o espaço sagrado no qual o ego do praticante se projeta e se dissolve, vivenciando as imagens ali representadas. É um "sistema quaternário, uma quadratura circuli ${ }^{9}$ (quadratura do círculo), cujos conteúdos procedem invariavelmente da dogmática lamaísta" (Jung, 1944/1990, p. 105). Plasticamente, podem ser representadas por uma série de círculos concêntricos inseridos num quadrado, que é englobado por outro círculo externo; em

4 Jung, em Memórias, Sonhos e Reflexões (1961/1985, p. 175) e no "Prefácio à Segunda Edição" de OSegredo da Flor de Ouro (1929/1983, p. 7) aponta o ano de 1928; em Psicologia e Alquimia (1944/1990, p. 109), o ano de 1929. Como O Segredo da Flor de Ouro foi publicado originalmente em fins de 1929, é possível que a correspondência de Wilhelm tenha sido encaminhada na virada do ano de 1928 para 1929.

5 Termo originário da Alquimia.

6 Lugar sagrado e protegido, onde a presença da divindade pode ser intuída. O temenos greco-romano consistia numa muralha cercando um lugar consagrado a alguma divindade; nos tempos helenísticos as ruas das cidades desembocavam em seus muros (Yeomans, 2006, p. 32).

7 Jung (1944/1990) cita a obra alquímica Rosarium philosophorum:“Com o homem e a mulher traça um círculo e extrai desse o quadrado; do quadrado extrai o triângulo.Traça um círculo e então terás a pedra dos filósofos" (p. 138). Essa é a "quadratura do círculo", citada mais adiante (vide Nota 10).

8 A escola Vajrayana, também conhecida como Tantrayana ou Mantrayana, significa, em sânscrito, "Veículo Diamante"; várias escolas do budismo esotérico se agregam sob essa denominação, que surgiu por volta do século V. As duas escolas mais importantes do budismo são a Mahayana (Grande Veículo) e a Hinayana (Pequeno Veículo) (Dragonetti \& Tola, 1995).

9 Essa expressão indicaria que o círculo é o limite da expansão do ponto primordial, metamorfoseando-se em quadrado ao final desse processo. 
geral o quadrado possui aberturas na porção mediana de cada um de seus lados, em conformidade com os pontos cardeais, simbolizando o plano ou planta baixa de um palácio ou templo. $O$ centro do mandala representa o vazio que subjaz toda experiência fenomênica, origem de toda a criação. Por isso os mandalas montados com areia são desfeitos após sua confecção, como um símbolo da impermanência de todas as coisas.

A origem do reconhecimento da importância desse símbolo em Jung é, em geral, atribuída ao seu contato com as mitologias e religiões do extremo Oriente, como o já citado budismo tibetano e também o hinduísmo, confucionismo e taoísmo, e também os mandalas cristãos da Idade Média, nos quais Cristo surge como o centro e os quatro evangelistas figuram nos pontos cardeais. Além disso, em seu texto de 1929, Jung cita místicos cristãos como Hildegard von Bingen (1098-1179) e Jacob Böhme (1575-1624) e povos indígenas, como os índios Pueblo do Novo México, como criadores de mandalas. Mesmo citando essas outras referências, ele reafirma que "os mandalas mais belos são os do budismo tibetano" (Jung \& Wilhelm, 1929/1983, pp.38-39). Fora os exemplos já comentados, em Psicologia e Alquimia Jung amplia suas referências, com as ilustrações presentes nos tratados alquímicos e o Calendário Asteca ou Pedra do Sol (Jung, 1944/1990, p. 107), entre outros.

Contudo, o depoimento de Bárbara Hannah ${ }^{10}$ - biógrafa de Jung e participante de seu círculo mais estreito - nos dá outra e pouco explorada faceta dessa história. Ela relata ter ouvido do próprio Jung a "vívida impressão" que lhe causou a visita a uma mesquita da cidade do Cairo em 1926. Nessa época Jung ainda não havia se certificado se o mandala era um símbolo universal, presente em todas as culturas, ou um símbolo específico de algumas culturas ou da subjetividade de determinados indivíduos; note-se que essa visita precede o sonho do qual derivou o mandala"A Janela para a Eternidade" e também seu contato com Wilhelm, que ele assinala em suas memórias como o momento decisivo para a elucidação desse simbolismo.

Por isso teria sido de grande importância a sua visita a essa mesquita, pois nela observou as mesmas características do mandala, concluindo então que esse símbolo também se manifestava no islamismo.

Mas foi somente em 1933 que Jung relatou aos seus alunos e colaboradores o que descobriu nessa viagem ao Egito, quando já tinha certeza da validade universal do mandala.

Hannah (1976/2003) nos conta o que ouviu:

Jung descreveu essa mesquita em detalhes, dizendo tratar-se de um quadrado perfeito com corredores muito belos e amplos, com pilastras, em cada lado. A Casa da Ablução, onde ocorriam os rituais de lavagem, encontrava-se no centro. Uma fonte de água jorrava formando o banho do rejuvenescimento, do renascimento espiritual. Jung descreveu as ruas empoeiradas e apinhadas do lado de fora e em 1961. 
afirmou que o amplo salão parecia a entrada da Corte Celestial, como se fosse o próprio céu. Ele teve a impressão de uma concentração perfeita e de ser aceito no imenso vazio do céu e essa religião, na qual Deus é realmente um chamado, finalmente tornou-se compreensível para ele. (pp.187-188)

Seguindo esse relato, não há dúvida de que o contato que Jung estabeleceu com esse temenos foi decisivo para a solidificação de seu conceito sobre o mandala, que se expressa de modo conclusivo em Psicologia e Alquimia:"Podemos afirmar agora que o símbolo do mandala é uma realidade psíquica autônoma, caracterizada por uma fenomenologia que se repete e é idêntica em toda a parte" (Jung, 1944/1990, p. 195).

Mas Jung era um homem que gostava de viajar e conhecer ambiências, costumes e crenças religiosas diversas, buscando um olhar exterior ao Ocidente, e esse não foi o seu primeiro, nem o último, contato significativo com o Islã.

\section{O Contato de Jung com o Islã}

O primeiro contato de Jung com a cultura islâmica ocorreu numa viagem à Tunísia no início de 1920. Em seu relato autobiográfico ele conta um sonho que teve na sua última noite em solo tunisiano, no qual ele se encontrava numa cidade árabe cercada de muralhas, em cujo centro havia um Casbah (forte) cercado por um fosso com água. Esse Casbah, ele relata, "é um mandala perfeito:fortim cercado de um muro quadrado, com quatro portas" (Jung, 1961/1985, p. 216).

Na mesma viagem, ao travar contato com uma manifestação sufi, Jung não a identificou como tal. Ele relata esse encontro que ocorreu próximo a Tozeur, no deserto de Nefta:

No extremo mais afastado do lugar, elevou-se de repente uma nuvem de poeira; um estandarte verde foi desdobrado e o tambor ressoou. À frente de uma longa fila de algumas centenas de homens de aparência selvagem... apareceu um venerável velho de barba branca, de uma dignidade natural e inimitável, que parecia ter tido sempre cem anos. Era o marabu11 montado em sua mula branca; em torno dele, os homens dançavam com tamborins. Por toda a parte, reinava a agitação, gritos selvagens e roucos, poeira e calor. Fanático e agitado, o bando passou diante de nós, saindo do oásis, como se partisse para um combate. Segui o tumulto a uma distância razoável, porque meu intérprete não achava conveniente que me aproximasse do lugar em que "trabalhavam".(Jung, $1961 / 1985$, p. 214)

11 Denominação dada a um chefe religioso ou líder espiritual no Norte da África, em especial no Magreb; a partir do século XIV os "marabit" ficaram associados ao sufismo, como líderes de ordens. 
Dezoito anos mais tarde, quando viajou à Índia, em 1938, Jung visitou o Taj Mahal' ${ }^{12}$ a capital do terceiro imperador mogol Jalaluddin Muhammad Akbar (1542-1605), mais conhecido como Akbar, o Grande, cujo reinado iniciou-se em 1556. Essa cidade, denominada Fatehpur Sikri, foi iniciada em 1569 e finalizada por volta de 1580; construída em honra do xeique sufi Salim Chishti (m.1572), foi edificada utilizando-se arenito vermelho e estuque, sendo abandonada mais tarde devido a problemas com o abastecimento de água potável. Desde então tem sido uma cidade-fantasma e encontrase ainda hoje em excelente estado de conservação. Sua técnica de construção pode ser descrita como "carpintaria em pedra", pois os blocos foram cortados com exatidão e colocados sem ou com um mínimo de argamassa (Cruickshank, 1896/2001, p. 620). A decoração dos edifícios conta com paisagens ${ }^{13}$ e motivos geométricos esculpidos diretamente sobre o arenito, e rendilhados em estuque. Ahmed (1994, p. 92) coloca:"Fatehpur Sikri é uma síntese da arquitetura hindu e islâmica". Por exemplo, as torretas levantadas nos quatro ângulos das edificações, denominadas chattri, são típicas da arquitetura hindu, conjugando assim o"estilo islâmico persa com a tipologia arquitetônica hindu" (Mandel, 1989, pp. 22-23). Entretanto, a decoração é em sua maior parte de origem islâmica, apesar de altamente estilizada por ter sido construída por artesãos hindus sob o comando de mestres persas (Cruickshank, 1896/2001, p.621).

Em Fatehpur Sikri, Jung pôde observar o Diwan-i-Khas (Salão da Audiência Privada), que é uma edificação cúbica ${ }^{14}$ com quatro torretas (Figura 1 ), em cujo centro encontra-se uma coluna ricamente decorada que sustenta uma plataforma; sobre o eixo da coluna encontra-se o trono circular elevado, uma semiesfera similar a um caldeirão, que possui um mandala desenhado em sua parte inferior interna. Quatro pontes que partem dos eixos diagonais conectam a plataforma a uma galeria periférica, que é alcançada por escadas em espiral situadas nas torretas nos cantos das paredes $^{15}$ (Cruickshank, 1896/2001, p. 621; Ching, 2007, p. 47). Acomodado nesse trono, Akbar ouvia seus conselheiros e filósofos alojados nas galerias dispostas ao longo das paredes, bem como emissários de outras religiões, pois o imperador era aberto a todas as crenças.

12 Também um monumento islâmico, o Taj Mahal foi finalizado em meados do século XVII para servir de mausoléu a Mumtaz Mahal, esposa do imperador Shah Jahan, neto de Akbar, o Grande. Shah Jahan também reconstruiu o mausoléu dedicado a Salim Chishti em Fatehpur Sikri por volta de 1610.

13 Paisagens compostas principalmente de árvores frutíferas e pássaros, imagens proibidas pelo Islã. Algumas delas foram parcialmente destruídas pela ação de muçulmanos contrários a essas representações.

14 Jung equivoca-se ao descrevê-la como possuindo forma circular.

15 Essa edificação é considerada "a unique architectural invention" (Cruickshank, 1896/2001, p. 621). 


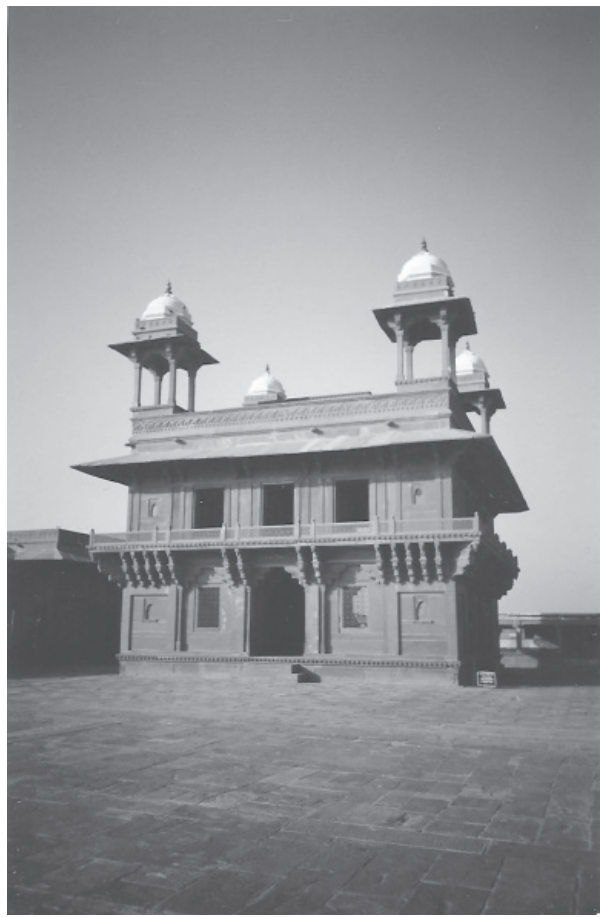

Figura 1. Edifício do Diwan-i-Khas em Fatehpur Sikri (Índia)

Inspirado por esse lugar, Jung teve outro sonho, no qual se encontrava numa sala cujo"conjunto era um gigantesco mandala, e correspondia exatamente ao Diwân-i-kass que eu visitara nas Índias"16 (Jung, 1961/1985, p. 192).

Entretanto, Jung não menciona em seu relato autobiográfico as impressões que teve de sua visita ao Cairo em 1926, embora especifique aspectos pontuais de suas visitas anteriores e posteriores ao mundo islâmico, como já colocado.

Desse modo, não temos uma referência direta, fornecida pelo próprio Jung, sobre sua visita à mesquita que estamos buscando. Qual das tantas mesquitas do Cairo se coaduna com a descrição relatada por Barbara Hannah?

Apesar dessa dificuldade, um trecho de sua obra Psicologia e Alquimia, que compara elementos do cristianismo, do hinduísmo e do islamismo, talvez nos aponte a solução desse enigma:

Citarei três exemplos famosos: os discípulos no caminho de Emaús, Krishna e pressionara fortemente como representação de um conteúdo em relação ao seu centro" (p. 192). 
Arjuna no Bhagavadgîta e Moisés e El-Khidr na sura 18 do Corão. Levo além a conjectura: o tesouro no mar, o companheiro e o jardim são uma mesma coisa, isto é, o Si-mesmo. O jardim é de novo o temenos, e a fonte, a nascente da "água viva" mencionada por João 7,38, a qual também foi procurada e encontrada pelo Moisés do Corão, com El-Khidr a seu lado, um de "nossos servidores, dotado de nossa graça e sabedoria" (sura 18). E segundo a lenda, no chão do deserto, em torno de El-Khidr brotaram flores primaveris. A imagem do temenos com a fonte, inspirada na antiga arquitetura cristã, tornou-se o pátio da mesquita islâmica, tendo ao centro a casa de banhos ritualística (por exemplo, Ahmed Ibn-Tulun, no Cairo). (Jung, 1944/1990, p. 129)

A menção à Mesquita Ahmad Ibn Tulun, em tal contexto, nos sugere que esse é o templo que Jung visitou e cuja descrição foi ouvida por Hannah. Mas será que sua arquitetura se assemelha de fato ao que foi descrito?

Para esclarecer esse ponto obscuro na biografia e na gênese da obra de Jung temos, a princípio, que dirigir nossa atenção para a metrópole cairota e para a Mesquita Ahmad Ibn Tulun em particular.

\section{A Dinastia Tulúnida e a Mesquita Ahmad Ibn Tulun}

Nossa busca se inicia pela história da islamização do Egito e da fundação da cidade do Cairo.

Em 639 da era cristã os exércitos árabes invadiram o Egito a mando do califa Omar, expulsando em 642 os persas sassânidas ${ }^{17}$ que dominavam a região. Uma nova capital foi fundada pelo comandante das forças árabes, Amr Bin al-As, no local de uma antiga fortificação romana, recebendo a denominação de al-Fustat ${ }^{18}$. O Egito foi então transformado numa província do califado omíada e posteriormente do califado abássida. Mais de dois séculos após esses eventos, Ahmad ibn Tulun (835-884) foi nomeado governador da província do Egito ao suceder seu padrasto em 870; nascido em Bagdá, era filho de um escravo turco de origem mongol que foi adotado posteriormente por Bavakbak, general do califa al-Mamun. Fundou a dinastia tulúnida (868-905), que garantiu ao Egito autonomia em relação ao califado abássida; oito anos depois ele dominou e anexou a Síria aos seus domínios (Castillo, Kostof, \& Tobias, 1995; Cruickshank, 1896/2001; Hourani, 1994; Yeomans, 2006).

Ibn Tulun fundou uma nova capital, denominada Catai (al-Qatai), para aquartelar suas tropas. Excelente administrador, ele introduziu muitas melhorias no local, como um aqueduto ${ }^{19}$ para trazer água do Nilo, um hos-

17 O Império ou Dinastia Sassânida - também conhecido como o Segundo Império Persa - foi definitivamente derrotado pelos exércitos do califado comandados por Khalid ibn Walid em 651, expandindo as fronteiras do Islã até a Ásia Central e parte da Índia.

18 Fustat provavelmente deriva do grego phossaton, que significa campo fortificado (Castillo et al., 1995, p. 363).

19 O Aqueduto de Basatin. 
pital para os pobres e um hipódromo; em 872 ele restaurou o Nilometer ${ }^{20}$, construído originalmente em 862 pelo califa al-Mutawakkil. Em 876 Ibn Tulun iniciou a construção de uma mesquita no Monte Yashkur ${ }^{21}$, finalizada em 879, que recebeu seu nome. Mas cinco anos depois Ibn Tulun faleceu devido a uma intoxicação proveniente do consumo de leite contaminado e foi sucedido pelo seu filho Khumaraweh que, por sua vez, foi assassinado em 896. Finalmente, em 905, após um período conturbado, o Egito retorna ao domínio de Bagdá e Catai é destruída pelas forças do califado abássida, sendo a Mesquita Ahmad Ibn Tulun o único monumento remanescente (Raymond, 2002; Robinson, 1996; Yeomans, 2006).

Em 969 os novos mandatários do Egito - a dinastia fatímida - decidiram fundar uma cidade próxima ao Nilo, al-Qahira (A Vitória), que dá origem à denominação atual Cairo. Essa povoação era relativamente distante da antiga capital tulúnida e, conforme a população que restava no local mudou-se para a nova cidade, Catai foi progressivamente abandonada até desaparecer por completo. Com o passar do tempo, a própria mesquita foi negligenciada, até cair em total abandono. A partir do século XII ela se tornou abrigo provisório anual (caravançará) para peregrinos da África do Norte em sua viagem a Meca, sendo bastante danificada. Deserta a maior parte do tempo, acabou por ser considerada mal-assombrada e era evitada por todos os habitantes da região. $O$ destino da mesquita sofreu uma reviravolta em 1296, quando serviu de esconderijo ao futuro sultão mameluco al-Mansour Husam Addin Lajin, que havia assassinado o então governador do Egito, o sultão al-Ashaf Khalil ibn Qalawun; Lajin permaneceu um ano homiziado no local e jurou que, se sobrevivesse, restauraria a mesquita ao seu original esplendor. Em 1297 ele tornou-se o mandatário do Egito e cumpriu sua promessa; seu sucessor, al-Nasir Addin Muhammad, iniciou a restauração do minarete em 1299 (Castillo et al., 1995; Cruickshank, 1896/2001; Macdonald, 1995; Yeomans, 2006).

Posteriormente, por volta do século XVIII, houve planos frustrados de se transformar a mesquita em um forte (Casbah), depois em um hospital e, mais tarde, foi alugada a tecelões, entre outras finalidades. Por volta de 1814 , com a expansão da cidade do Cairo, a muralha externa foi utilizada como apoio para a construção de casas e lojas e somente em 1890 a mesquita foi reconhecida como um importante monumento histórico. Apesar desse reconhecimento a ocupação irregular continuou e, no início do século XX, a mesquita não podia mais ser avistada de fora, estando totalmente encoberta pelas edificações atópicas. A partir de 1928 todas as construções adjacentes à muralha foram retiradas, com a exceção da Casa

20 Localizado na ilha de Rawdah, servia para medir a altura das águas do Nilo durante a inundação anual, determinando a política de irrigação. É o monumento islâmico mais antigo do Cairo na atualidade.

21 Gebel Yashkur (Monte de Ação de Graças). Segundo uma lenda local, lugar onde a Arca de Noé aportou após o Dilúvio; conforme o historiador al-Maqrizi, teria sido o lugar onde Moisés conversou com Deus (Akkach, 2005, p. 170). 
da Mulher Cretense $e^{22}$ (Beit al-Kritliyya), importante exemplo da arquitetura doméstica islâmica do século XVII, que ainda hoje permanece no local com o nome de Museu Gayer-Anderson, nome de seu último morador e restaurador. Atualmente a mesquita localiza-se no distrito de Sayyida Zeinab, no interior da denominada Cairo Islâmica ${ }^{23}$ (Behrens-Abouseif, 1998; Macdonald, 1995; Yeomans, 2006).

Em termos cronológicos, Ahmad Ibn Tulun foi a terceira mesquita a ser construída no Cairo e é a mais antiga remanescente na atualidade. Possui um projeto arquitetônico inovador, pois foi a primeira mesquita a possuir arcos em ponta, que depois foram denominados no Ocidente "arcos góticos"24:"Esses exemplos de arcos em ponta antecedem quase todos os exemplos europeus por cerca de três séculos" (Cruickshank, 1896/2001, p. 591). Tal como a Grande Mesquita de Samarra ${ }^{25}$, no atual Iraque, foi construída com tijolos de barro vermelho de excelente qualidade, evitando-se a reutilização de pedras de outros monumentos pré-existentes para a confecção de colunas, segundo uma arquitetura hypostyle ${ }^{26}$, i.e., empregando um grande número de colunas, como uma floresta, para suportar uma cobertura plana. Possui um total de 26.318 metros quadrados de área e é cercada por uma muralha crenelada medindo 118 por 138 metros, que separa o espaço sagrado das ruas agitadas que a circundam. Entre a muralha e o prédio da mesquita - com exceção do lado qibla ${ }^{27}$, i.e., voltado para Meca - existem corredores denominados ziyadas (Figura 2), com aproximadamente 19 metros de largura.

O plano arquitetônico da mesquita (Figura 3) é baseado na superposição de dois retângulos sobre um quadrado. No centro da construção há

22 Localizada adjacente ao canto sudeste da muralha externa da mesquita, essa edificação possui importância histórica por abrigar um reservatório do qual a água era distribuída aos habitantes locais. Na sua atual configuração foi incorporada outra residência denominada Beit Anna bint Salin. Teria sido construída sobre o local onde pretensamente foi enterrado Haroun al-Husseini, um famoso xeique sufi ou, noutra versão, al-Hussein, o neto do Profeta. Várias lendas estão a ela relacionadas, entre as quais que o poço em seu interior teria sido o local por onde as águas do Dilúvio escoaram, e que também seria a porta de entrada do palácio do "Rei dos Gênios" (Jinn).

23 Próximos a ela localizam-se outros monumentos importantes, como a Madrassa Sun-qur Sa'adi e o Teatro Mevlevi (Mevlevi Sama 'Khana), edificação circular feita em madeira, antigo local de reunião dos dervixes dançarinos.

24 Segundo Yeomans (2006), o edifício do Nilometer "já possuía os arcos em ponta que seriam denominados arcos góticos três séculos mais tarde" (p.30) e, conforme o historiador al-Qadi al Qalqashandi (m.1412), os arcos teriam sido usados para substituir as colunas de pedra na sustentação do teto. Os arquitetos da Mesquita de Samarra e da Mesquita de Abu Dulaf (c.860) teriam repetido os arcos nelas presentes na Mesquita Ahmad Ibn Tulun (Cruickshank, 1896/2001, p. 588).

25 Também conhecida como Mesquita al-Mutawakkil, foi construída em 852 pelo mesmo califa que originalmente edificou o Nilometer.

26 Consiste basicamente em um pátio central (sahn) circundado por quatro fileiras de colunas (riwaqs) (Yeomans, 2006, p. 32). O Grande Átrio em Karnak, Egito, é o exemplo mais antigo dessa arquitetura; a Mesquita de Córdoba, na Andaluzia, é outro exemplo magnífico.

27 "Qibla" significa "centro" em árabe; o centro do mundo para o Islã é a Caaba, localizada em Meca. No caso da Mesquita Ahmad Ibn Tulun é o lado leste. 


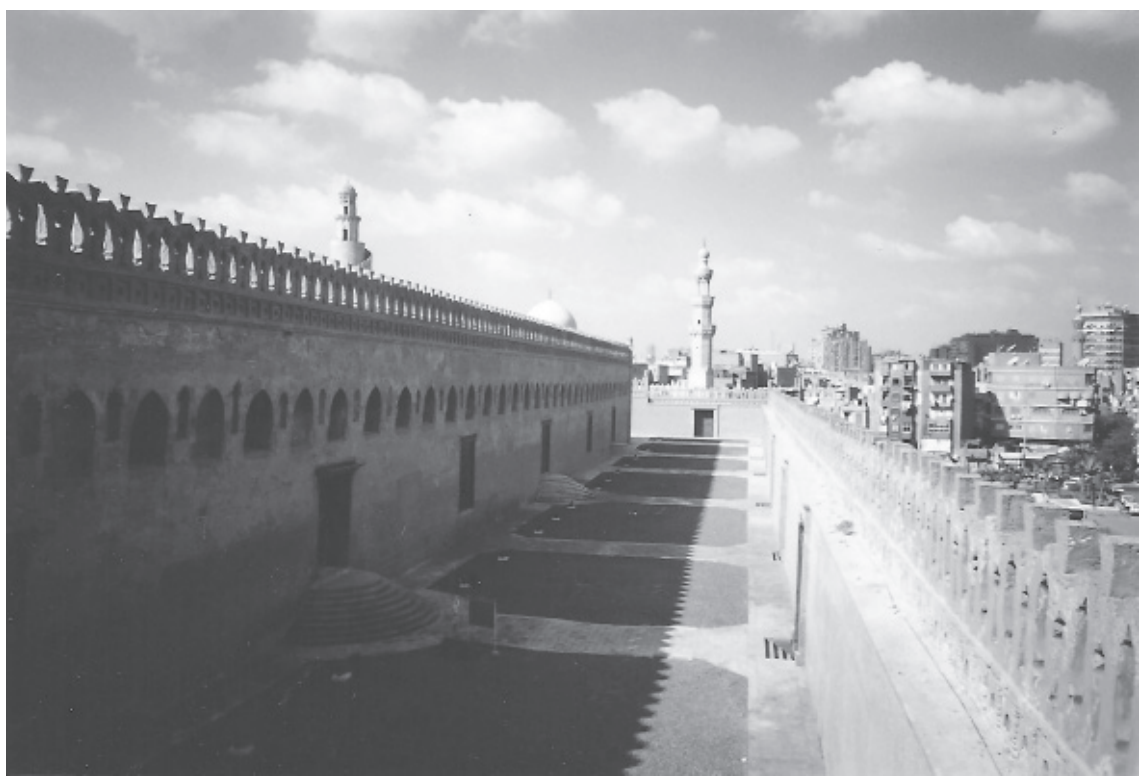

Figura 2. Corredor (Zyada) Sul da Mesquita Ahmad Ibn Tulun (Egito)

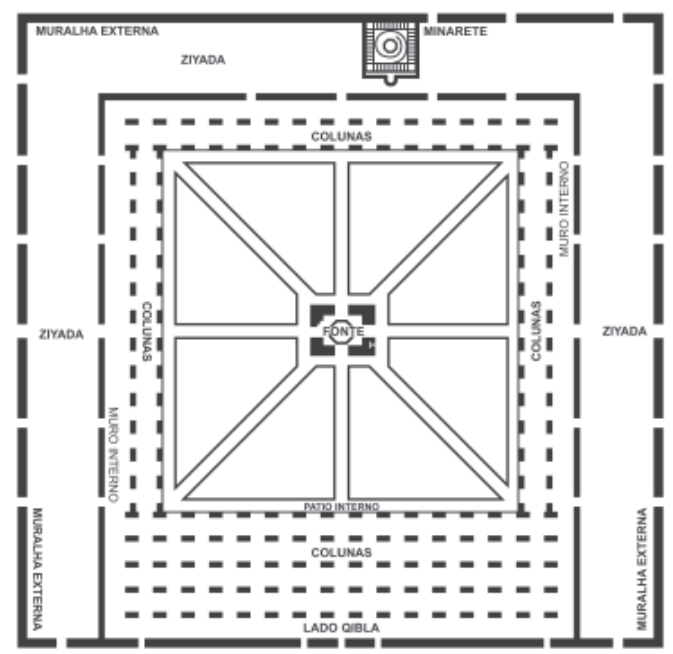

Figura 3. Plano Arquitetônico da Mesquita Ahmad Ibn Tulun (Egito)

um grande pátio aberto (sahn), medindo 92 por 92 metros. No pavimento desse pátio interno está desenhada uma estrutura radial, através do emprego de dois tipos de pedras de tonalidades contrastantes, que conduzem ao centro do pátio.

No centro do pátio existe uma edificação cúbica (Figura 4), encimada por uma estrutura octogonal com degraus e coberta por um domo, con- 


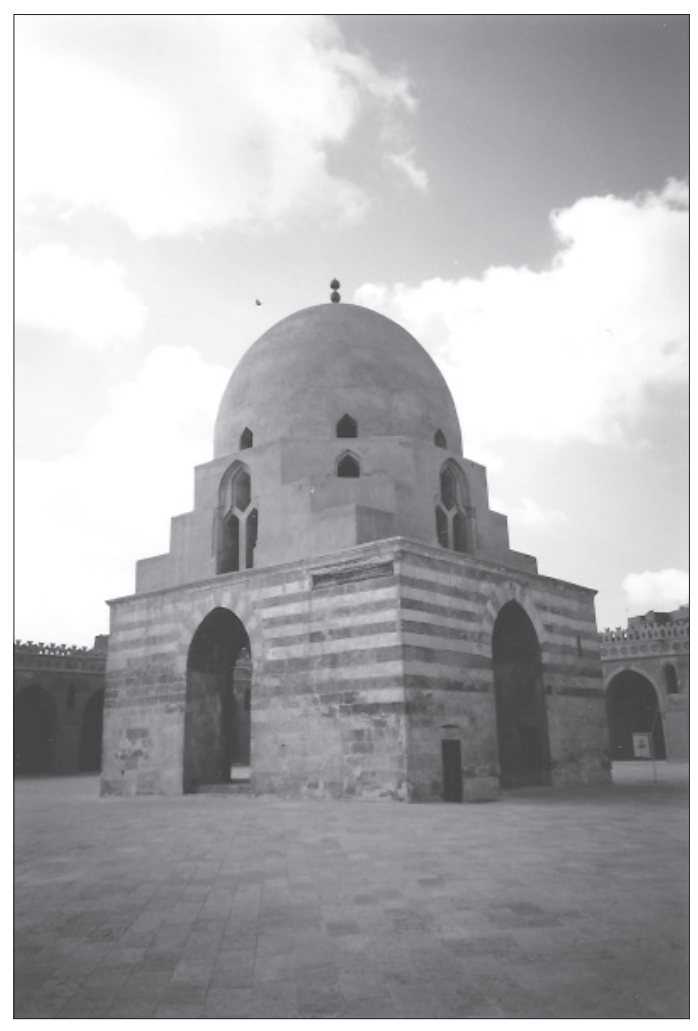

Figura 4. Edificação Sobre a Fonte da Mesquita Ahmad Ibn Tulun (Egito)

tando com quatro arcos em ponta de cada lado, quatro janelas sobre os arcos e doze pequenas aberturas em sua parte superior; no lado interno há uma bacia octogonal com a fonte em seu centro. Embora esteja harmonicamente integrada ao conjunto da mesquita, pelas suas proporções e simplicidade de forma, essa edificação possui algumas características da arquitetura mameluca ${ }^{28}$, visto que foi o sultão Lajin que substituiu a antiga estrutura que havia sido danificada pelo fogo em 986.

O historiador Ibn Duqmaq (citado por Yeomans, 2006) descreve sua antiga aparência: "A fauwara (fonte ornamental) ficava no meio do sahn (pátio interno) e sobre ela havia um domo dourado sobre dez colu- 
nas de mármore e ao seu redor 16 colunas de mármore com um piso de mármore" 29 (p. 34).

Ao longo de cada lado do pátio foram construídos treze arcos duplos suportados por colunas quadradas - excetuando-se de novo o lado qibla, que possui cinco fileiras de arcos - e sobre esses arcos foi construído um teto, formando arcadas. No lado qibla foi construída uma cobertura, para além das arcadas, que termina numa parede onde fica o mihrab, um espaço côncavo cavado nos tijolos apontando a direção de Meca; neste lado também se localiza o minbar, o púlpito para o imã se dirigir aos fiéis, reconstruído no século XIII pelo sultão Lajin. Duas portas laterais ao mihrab dão acesso ao Dar-al-Imara, conjunto de três aposentos adjacentes à área privada (maqsura) reservada aos mandatários e suas famílias.

Entre os arcos que delimitam o pátio interno existem 52 aberturas com colunelos; na face voltada ao pátio, cada uma delas é ladeada por dois motivos geométricos idênticos (104 no total) tendo por base o círculo e com o ponto central da circunferência em alto-relevo ${ }^{30}$. Do lado interno, os arcos possuem um friso com motivos florais e, sobre eles, inscrições em cúfico $^{31}$ retiradas do Alcorão e gravadas sobre tábuas de sicômoro ${ }^{32}$.

Fechando as arcadas, grossas paredes creneladas separam o interior da mesquita dos corredores externos, com 128 janelas em linha, próximas ao teto, por toda sua extensão e com 18 portas que se abrem para as ziyadas. Os vãos das janelas são cobertos por rendilhados de estuque, cada um deles com um desenho diferente, nos quais predominam os motivos do círculo e do triângulo. Do lado externo, as portas são alcançadas através de uma escada semicircular e entre as janelas existem 64 nichos representando conchas em baixo-relevo.

No corredor do lado oeste, oposto ao qibla, foi construído um minarete apoiado sobre uma base cúbica ${ }^{33}$, com uma rampa em espiral em sentido anti-horário, inspirado provavelmente nos minaretes helicoidais de Samarra ${ }^{34}$ e Abu Dulaf no Iraque, os quais, por sua vez, têm origem nas torres espiraladas para a adoração do fogo dos persas ${ }^{35}$ e nos zigurates ${ }^{36}$

29 Ibn Duqmaq (citado por Yeomans, 2006) também descreveu seu aspecto interno:“And under the dome was a great basin of marble 4 cubits in diameter with a jet of marble in the centre... and in the roof was a sundial. The roof had a railing around it of teakwood" (p. 34).

30 O círculo engloba dois triângulos equiláteros superpostos, um deles invertido, com os lados do triângulo inferior em forma de arcos, formando no seu conjunto um hexagrama inserido dentro de um círculo Esse símbolo assemelha-se ao Selo de Salomão, muito empregado como motivo decorativo e simbólico na arte e na arquitetura islâmica e que também aparece nas decorações de Fatehpur Sikri.

31 A mais antiga caligrafia árabe.

32 Figueira do Egito. Uma lenda local diz que as tábuas provêm da Arca de Noé.

33 A abrupta verticalidade do minarete contrasta com a amena horizontalidade das arcadas, numa "requintada correspondência" (Mandel, 1989, p. 16).

34 O minarete de Samarra é denominado malwiyya.

35 Por exemplo, o Templo do Fogo próximo à Tumba de Dário (485 a.C.) (Cruickshank, 2001, p. 98).

36 Estruturas piramidais construídas em camadas para fins religiosos na Mesopotâmia pelos sumérios, babilônicos e assírios, datando as mais antigas que se tem notícia cerca de três milênios antes de Cristo. 
mesopotâmios. Não se sabe exatamente a disposição da antiga cidade de Catai em relação à mesquita, mas já foi sugerido que todas as ruas da cidade convergiam em direção às portas de entrada da muralha externa, de forma semelhante ao temenos helenístico (Behrens-Abouseif, 1998; Cresweel, 1989; Yeomans, 2006).

Os historiadores Ibn Duqmaq, al-Maqrizi e al-Ya'qubi (citados por Yeomans, 2006, p. 33) relataram que Ibn Tulun enrolou um pedaço de papel em seu dedo e determinou que os construtores copiassem a forma resultante no minarete. Contudo, tal espontaneidade na edificação de um templo seria bastante improvável. Discute-se também se o minarete atual, devido à sua falta de alinhamento em relação à fonte, foi uma adição posterior à mesquita. Entretanto, a ausência de uma inscrição inaugural no próprio minarete parece demonstrar exatamente o contrário.

$O$ arquiteto ou arquitetos da mesquita são desconhecidos e também não possuímos referências diretas e conclusivas sobre os simbolismos da edificação.

Segundo o historiador al-Balawi ${ }^{37}$ (citado por Yeomans, 2006, p. 30), o copta ${ }^{38}$ que construiu o Aqueduto de Basatin também teria desenhado a Mesquita Ahmad Ibn Tulun.

Mas é improvável que isso seja um fato histórico, pois a mesquita possui uma concepção arquitetônica coerente com a tradição islâmica. Por outro lado, um registro atribuído ao cronista, geógrafo e historiador al-Ya'qubij ${ }^{39}$, contemporâneo da construção da mesquita, relata que o seu plano arquitetônico baseado no quadrado adveio de um sonho do próprio Ibn Tulun. Entretanto, essa história, tal como outras relacionadas à edificação da mesquita, é provavelmente apócrifa. O mais aceito pelos historiadores atualmente é que a concepção da mesquita foi trazida de Samarra, de onde vieram muitos artesãos para construí-la. E essa sensibilidade espiritual em ordenar espaços e edificações de forma simbólica é mais pré-moderna que propriamente islâmica, visto a notável influência que recebeu das concepções arquitetônicas helenísticas e persas. Além disso, o emprego de tijolo e estuque era a forma de construção tradicional da Mesopotâmia e possui raízes pré-islâmicas (Akkach, 2005; Yeomans, 2006).

De qualquer forma, a Mesquita Ahmad Ibn Tulun se destaca das demais mesquitas do Cairo pelas suas características ímpares, pois é"a maior, a mais velha, e em termos de grandeza, dignidade e simplicidade monumental, a mais refinada no Egito" (Yeomans, 2006, p. 31). também relataram eventos relacionados à Mesquita Ahmad Ibn Tulun.

38 Cristão egípcio.

39 Ahmad ibn Wadih al-Ya'qubi (m.897) escreveu as "Crônicas de Ibn Wadih" (Tarikh Ibn Wadih), relatando de forma romanceada personagens e acontecimentos de sua época. 


\section{Conclusão}

A partir dos elementos levantados nesse estudo, é evidente a correspondência entre a descrição de Jung relatada por Barbara Hannah e o plano arquitetônico da Mesquita Ahmad Ibn Tulun.

A localização, a planta baixa referenciada ao quadrado, os corredores, o pátio central com a fonte exatamente no seu centro, são todos elementos convergentes que, somados à citação em Psicologia e Alquimia, nos levam a supor com razoável grau de convicção que a edificação visitada por Jung no Cairo em 1926 foi de fato a Mesquita Ahmad Ibn Tulun.

Mas o que levou Jung a praticamente a esquecê-la ou ao menos não Ihe dar a devida importância em seus escritos e em seu relato autobiográfico, apesar da forte impressão que ela Ihe causou, como Barbara Hannah nos descreveu?

Lapso de um homem idoso com muito a contar? Ou talvez o contato ulterior com o texto de Wilhelm eclipsou a impressão da mesquita, visto terem ocorrido tão próximos? Não temos elementos para solver essa dúvida.

Apesar disso, podemos aventar uma hipótese: a dificuldade em se obter referências sobre a mesquita - pois a maior parte do que sabemos atualmente sobre ela estava em árabe à época ${ }^{40}$, língua que Jung desconhecia - fez com que ele desistisse de discorrer a respeito do assunto por falta de informações. Inclusive, só foi depois da sua visita ao Cairo que as autoridades egípcias iniciaram a efetiva restauração desse monumento da arquitetura islâmica e não seria de se estranhar que pouco houvesse a ser informado aos visitantes sobre uma história que a maioria dos habitantes locais olvidara.

Talvez esse possa ser o principal motivo para que reste somente a menção en passant em Psicologia e Alquimia referente à Mesquita Ahmad Ibn Tulun, enquanto outros monumentos mereceram maior destaque e comentários mais alentados na obra e nas memórias de Jung.

Assim, entendemos porque Jung equivocou-se ao afirmar, por exemplo, que a fonte ${ }^{41}$ serviria para as abluções rituais, pois na verdade as abluções realizavam-se fora dos muros da mesquita. Pelo material histórico a que temos acesso atualmente pode-se dizer que a finalidade da fonte é, ao mesmo tempo, ornamental (visível) e simbólica (invisível). Outro equívoco reside na sua afirmação de que a concepção do pátio da mesquita é originada da "antiga arquitetura cristã". Essa tese não se mantém face ao que sabemos hoje, pois a influência islâmica mais distante provém da Mesquita do Profeta em Medina (Arábia Saudita), antiga moradia de Muhammad, e posteriormente das mesquitas de Samarra e Abu Dulaf (Iraque). Todavia vale destacar que o plano baseado num centro estacionário (o pátio aber-

40 Cabe colocar que o clássico A History of Architecture, de Sir Banister Fletcher, foi editado originalmente em 1896. Todavia não consta da bibliografia de Psicologia e Alquimia.

41 A água que abastece a fonte é trazida por encanamentos, originalmente através de um aqueduto, já que no local não existe uma nascente. 
to) também é característico da arquitetura persa sassânida e possui antecedentes na arquitetura do Antigo Egito ${ }^{42}$.

Do mesmo modo, Jung não faz nenhuma menção ao lugar mais sagrado do Islã, seu omphalos ${ }^{43}$, a Caaba localizada em Meca, que é um templo cúbico cobrindo a "pedra negra" 44 e ao redor do qual os crentes devem circular."Caaba",entre outras acepções, significa "cubo" em árabe e era originalmente um lugar de adoração pagã. Na versão religiosa e popular, o primeiro templo teria sido construído nesse local por Abraão e Ismael; entretanto, a construção atual data de 608 . O templo permanece sempre coberto por um pano negro com brocados em ouro (kiswa) e está situado no centro da Mesquita Al Masjid Al-Haram, que foi construída a mando do califa Omar (634-644). Em 777 o califa al-Mahdi (775-785) ordenou a sua reconstrução, de forma que a Caaba ficasse no centro do pátio interno ${ }^{45}$, de maneira análoga à fonte na Mesquita Ahmad Ibn Tulun (Akkach, 2005; Cresweel, 1989; Shah, 1992).

Jung também ignorou outro monumento muito importante na tradição islâmica ${ }^{46}$, o Domo da Roch $a^{47}$ em Jerusalém, que é uma edificação octogonal que circunda e sustenta uma cúpula ${ }^{48}$, com estritas proporções matemáticas na sua concepção arquitetônica, pois todas as dimensões do octógono estão relacionadas com o círculo central e cada parede externa possui a mesma medida do diâmetro do domo, que também é igual à altura do domo em relação ao tímpano ${ }^{49}$. Cada parede externa possui sete janelas e uma porta, remetendo ao número oito, com exceção da parede onde está a porta principal. No seu interior existe um segundo octógono apoiado em colunas coríntias, com as mesmas dimensões do octógono externo, que delimita dois corredores circulares (deambulatórios), nos quais os fiéis devem realizar um movimento de circum-ambulação ao redor da

42 Por exemplo, em Tell el-Amarna (XVIII dinastia, século XIV a.C.) o santuário do deus Áton possuía sucessivos pátios "abertos aos raios da divindade" (Español, 1992, p. 54).

43 Centro do mundo.

44 Em árabe, "hajar el aswad".Em árabe o termo"fehm",significa"negro"e também"sabedoria" ou "conhecimento";"negro" designa igualmente o Egito, devido à cor de seu solo. Por isso, a"arte negra" ou "arte egípcia" é a "arte da compreensão" (Shah, 1992, pp. 212-214).

45 Originalmente medindo 196 por 142 metros. Várias outras remodelações e ampliações foram realizadas posteriormente.

46 "The Dome of the Rock with the 'Profet's mosque' and the Kaaba is among the most important Muslin shrines" (Cruickshank, 1896/2001, p. 581).

47 Em árabe, Qubbat as-Sakhrah. Finalizado em 691, não é uma mesquita, mas um templo para peregrinos (mashhad).

48 Foram os persas sassânidas que solucionaram o problema de construir um domo esférico sobre uma base cúbica, empregando o artifício de instalar arcos ("squinch" arches) sobre cada canto do cubo, convertendo-o assim num octógono; o palácio de Firouzabad ou Feruzabad, no atual Irã, é a edificação mais antiga conhecida na qual essa técnica foi empregada (Cruickshank, 1896/2001, p. 97).

49 Termo arquitetônico que descreve o espaço triangular limitado pelos lados do frontão. A sustentação do domo é descrita em Cruickshank (1896/2001, p. 581): "Its high timber dome was carried on a stone arcade of pointed arches on Corinthian columns alternating with marblefaced piers." 
rocha sagrada da qual, segundo a tradição islâmica, Muhammad ascendeu aos céus (Akkach, 2005; Cresweel, 1989; Shah, 1992).

Essas duas edificações podem ser consideradas exemplos arquitetônicos que configuram mandalas perfeito ${ }^{50}$, tal como a Mesquita Ahmad Ibn Tulun, que assim estaria vinculada a essa tradição que se remete à formação das primeiras irmandades sufis, relacionando cosmologia e arquitetura (Akkach, 2005, pp.3-4).

Esse vínculo é explicitado na concepção arquitetônica da edificação que cobre a fonte da Mesquita Ahmad Ibn Tulun, onde podemos encontrar a junção das formas geométricas da Caaba (cubo) e do Domo da Rocha (octógono e esfera), configurando uma composição concêntrica baseada num centro estacionário (eixo) que se desenvolve a partir de um polígono regular (Akkach, 2005, pp. 152-155). E apesar dessa edificação ser posterior ao plano original da mesquita, ela mantém seu espírito ao trabalhar sobre os fundamentos arquitetônicos tradicionais do Islã ${ }^{51}$.

Não é de se estranhar, então, que inexista referência ao Sufismo em Psicologia e Alquimia ${ }^{52}$; de igual feita, ao se referir a Khidr, o Verde ${ }^{53}$, no trecho citado anteriormente sobre $A$ Sura da Caverna (Suratu Al-Kahf) ou Sura 18 do Alcorão, Jung parece não se dar conta de que ele é o patrono dos sufis e que no Ocidente é identificado com São Jorge, patrono da Ordem da Jarreteira na Inglaterra e de muitas outras irmandades ao redor do mundo (Shah, 1992, pp. 244-245).

Jung também não fez referência à predominância dos números pares no plano da mesquita, o que poderia ser uma alusão à divindade como dualidade de oposto ${ }^{54}$, conduzindo à circum-ambulação simbolizada pelo minarete helicoidal a girar em sentido anti-horário, movimento que na teoria junguiana caracteriza o inconsciente. Quanto a isso, Jung (1944/1990) pondera que"logo que a consciência e o inconsciente entram em contacto, os opostos que eles contêm se repelem.... A consciência é exortada à 'circumambulatio' a fim de suportar a tensão,... formando esse círculo protetor" (p.159). Reforçando essa idéia, o símbolo circular gravado sobre os arcos ao longo do pátio interno é igualmente uma imagem mandálica que reproduz a concepção arquitetônica da mesquita, com a fonte da criação e do conhecimento em seu centro. Para Jung (1944/1990),"o centro do mandala

50 Entre outros exemplos artísticos, uma miniatura de origem persa do século XVI denominada A Imagem da Caaba, que se encontra atualmente em Paris no acervo da Bibliothèque Nationale de France, possui uma concepção formal similar ao khilkor tibetano.

51 Como a divisão entre espaços sacros e profanos não fazia sentido na perspectiva islâmica pré-moderna, também cidades como Bagdá, al-Basra e al-Kufa foram construídas ao redor de um eixo central (Akkach, 2005, p. 169). Mas provavelmente essa concepção se inspirou no plano da cidade de Firouzabad, no Império Sassânida.

52 Mesmo em seu último livro - Mysterium Coniunctionis (Mistério da União), editado postumamente em 1968 e que avança na análise sobre a Alquimia - inexiste menção ao Sufismo.

53 Jung fica muito aquém da penetrante análise de Corbin (1958/1997, pp. 53-67) sobre Khidr.

54 Tese atribuída a Dhu'l-Nun al-Misri, o Egípcio (m. c.860), um dos mais respeitados mestres sufis clássicos, "suposto fundador da ordem dos dervixes construtores" (Shah, 1992, p. 212) e decifrador dos hieróglifos egípcios (El Daly, 2005). 
corresponde ao cálice de lótus indiano: sede e local da origem dos deuses" (p. 191, n. 127).

Outro aspecto que com certeza chamaria a atenção de Jung seria o relato de al-Ya'qubi vinculando a concepção da mesquita com um sonho do próprio lbn Tulun, pois isso confirmaria a noção de que os símbolos da psique objetiva surgem espontaneamente na atividade onírica, como ele procura demonstrar em Psicologia e Alquimia (Jung, 1944/1990, pp. 53-56).

Sem que se pretenda esgotar as associações e as interpretações sobre o significado, ou múltiplos significados, dos elementos arquitetônicos, estilísticos e simbólicos presentes na Mesquita Ahmad Ibn Tulun em particular e na arquitetura islâmica em geral, o que fugiria ao escopo do presente artigo, fica evidente a razão do enleio que ela provocou em Jung.

Embora esse seu arrebatamento fosse de natureza intuitiva, através de nossa análise procuramos demonstrar que a mesquita possui inúmeras características que viriam a interessar sobremaneira a Jung, visto que são, em muitos pontos, coincidentes com sua abordagem teórica.

Assim, pode-se afirmar que, apesar de Jung tê-la aparentemente esquecido, a Mesquita Ahmad Ibn Tulun foi de importância decisiva na formulação de suas idéias e, mesmo ainda hoje, sua história, sua arquitetura e seus simbolismos nos inspiram e transmitem essa filosofia perene, narrada em barro e estuque, que atravessa os milênios.

\section{Jung, Mandala and Islamic Architecture}

Abstract: This article intends to reflect on the origins of the Jungian concept of mandala. The autobiography of Jung, Memories, Dreams, Reflections, and his work Psychology and Alchemy are utilized to trace that origin. According to Barbara Hannah, biographer of Jung, a mosque in Cairo (Egypt) was of utmost importance for the formulation of this concept. Probably, this temple is the Mosque Ahmad Ibn Tulun. The relationship between the Islamic architectural symbolism inspired by Sufism and the psychological conceptions of Jung is analyzed.

Keywords: Jung, Carl Gustav, 1875-1961. Mandala. Islamic Architecture. Mosque Ahmad Ibn Tulun. Sufism.

\section{Jung, Mandala et Architecture Islamique}

Résumé: Cet article se propose de réfléchir sur l'origine de le concept junguienne de mandala. On utilize l'autobiografie de Jung, Mémoires, Rêves, Réflexions, et son ouvre Psychologie et Alchemie pour tracer cette origine.Chez Barbara 
Hannah, biographe de Jung, une mosquée à Caire (Égypte) a été d'importance capital pour la formulation de ce concept. Probablement cette temple est la Mosquée Ahmad Ibn Tulun. On analise la relation entre le symbolism architectonique islamique inspiré par le soufisme et les conceptions psychologiques de Jung.

Mots-clés: Jung, Carl Gustav, 1875-1961. Mandala. Architecture Islamique. Mosquée Ahmad Ibn Tulun. Soufisme.

\section{Jung, Mandala y Arquitectura Islámica}

Resumen: Este artículo se propone a reflexionar sobre los orígenes del concepto junguiano de mandala. Se utiliza el relato autobiográfico de Jung, Memorias, Sueños y Reflexiones, y su obra Psicología y Alquimia para buscar esa origen. Según Barbara Hannah, biógrafa de Jung, una mezquita en Cairo (Egipto) fue de importancia fundamental para la formulación de ese concepto. Es probable que este templo sea la Mezquita Ahmad Ibn Tulun. Es analizada la relación entre la simbología arquitectónica islámica inspirada por el sufismo y las concepciones psicológicas de Jung.

Palabras clave: Jung, Carl Gustav, 1875-1961. Mandala. Arquitectura Islámica. Mezquita Ahmad Ibn Tulun. Sufismo.

\section{Referências}

Ahmed, A. S. (1994). Living Islam: From samarkand to stornoway. New York: Facts On File.

Akkach, S. (2005). Cosmology and architecture in pre-modern Islam: An architectural reading of mystical ideas. New York: State University of New York Press.

Behrens-Abouseif, D. (1998). Islamic architecture in Cairo: An introduction. Cairo: The American University in Cairo Press.

Castillo, G., Kostof, S., \& Tobias, R. (1995). A history of architecture: Settings and rituals. Oxford: Oxford University Press.

Ching, F. D. K. (2007). Architecture: Form, space \& order. Hoboken, NJ: John Wiley \& Sons.

Corbin, H. (1997). Alone with the alone: Creative imagination in the Sufism of Ibn 'Arabi. Princeton: Princeton University Press. (Trabalho original publicado em 1958)

Creswell, K. A. C. (1989). A short account of early Muslin architecture. Aldershot, UK: Scholar Press. 
Cruickshank, D. (Ed.). (2001). Sir Banister Fletcher's a history of architecture (20a ed.). Oxford: Architectural Press. (Trabalho original publicado em 1896)

Dragonetti, C., \& Tola, F. (1995). On voidness: A study on Buddhist nihilism. Delhi: Motilal Banarsidass.

Español, F. (1992). Saber ver a arte egípcia (I. Benedetti, trad.). São Paulo: Martins Fontes.

El Daly, O. (2005). Egyptology: The missing Millennium. Ancient Egypt in medieval Arabic writings. Walnut Creek, CA: Left Coast Press.

Hannah, B. (2003). Jung: vida e obra - uma memória biográfica (A. Fillmann, trad.). Porto Alegre: Artmed. (Trabalho original publicado em 1976)

Hourani, A. (1995). Uma história dos povos árabes (M. Santarrita, trad.). São Paulo: Companhia das Letras.

Jung, C. G. (1985). Memórias, sonhos, reflexões (D. F. da Silva, trad.). Rio de Janeiro: Nova Fronteira. (Trabalho original publicado em 1961)

Jung, C. G. (1990). Psicologia e alquimia (M. L. Appy, trad.). Petrópolis, RJ: Vozes. (Trabalho original publicado em 1944)

Jung, C. G., \& Wilhelm, R. (1983). O segredo da flor de ouro (D. F. da Silva \& M. L. Appy, trads.). Petrópolis, RJ: Vozes. (Trabalho original publicado em 1929)

Macdonald, F. (1995). Ibn Tulun: The story of a mosque. Cambridge: Hood Hood Books.

Mandel, G. (1989). Como reconhecer a arte islâmica (C. Carvalho, trad.). Lisboa: Edições 70.

Raymond, A. (2002). Cairo: An illustrated history. Nova York: Rizzoli.

Robinson, F. (1996). Cambridge illustrated history of the Islamic world. Cambridge: Cambridge University Press.

Shah, I. (1992). Os sufis (O. M. Cajado, trad.). São Paulo: Cultrix.

Yeomans, R. (2006). The art and architecture of Islamic Cairo. Dryden, NY: Ithaca.

Rafael Raffaell, Doutor em Psicologia Clínica pela Pontifícia Universidade Católica de São Paulo. Professor Titular em Psicologia Clínica do Departamento de Psicologia da Universidade Federal de Santa Catarina - UFSC. Professor do Quadro Permanente do Doutorado Interdisciplinar em Ciências Humanas da UFSC. Endereço para correspondência: Rua Aracuã, 351, Pantanal, Florianópolis, SC. CEP 88040-310. Tel/Fax: (48) 3721-8559. Endereço eletrônico: raraffa@terra.com.br.

Recebido em: 29/02/2008

Aceito : 26/05/2008 